\title{
Celastrol negatively regulates cell invasion and migration ability of human osteosarcoma via downregulation of the PI3K/Akt/NF-кB signaling pathway in vitro
}

\author{
XIAOLONG YU $^{1 *}$, QIANG WANG $^{1 *}$, XIN ZHOU $^{1}, \mathrm{CHANGLIN} \mathrm{FU}^{1}$, MING CHENG $^{1}$, \\ RUNSHENG GUO ${ }^{2}$, HUCHENG LIU ${ }^{2}$, BIN ZHANG ${ }^{1}$ and MIN DAI ${ }^{1}$ \\ ${ }^{1}$ Department of Orthopedics, The First Affiliated Hospital of Nanchang University, Artificial Joints Engineering and \\ Technology Research Center of Jiangxi Province; ${ }^{2}$ Multidisciplinary Therapy Center of Musculoskeletal Tumor, \\ The First Affiliated Hospital of Nanchang University, Nanchang, Jiangxi 330006, P.R. China
}

Received May 18, 2015; Accepted June 27, 2016

DOI: $10.3892 / \mathrm{ol} .2016 .5049$

\begin{abstract}
Osteosarcoma (OS) is a primary malignant tumor of the bone, with a tendency to metastasize early. Despite the advances in treatment options, more than $30 \%$ of patients develop distant metastases, and the prognosis of these patients with metastases is extremely poor. Celastrol has been demonstrated to manifest multiple pharmacological activities, including induction of apoptosis in numerous types of cancer cell lines. Our previous studies have also suggested that Celastrol is capable of inducing apoptosis of human osteosarcoma cells via the mitochondrial-dependent pathway. The purpose of this study was to investigate the effects of Celastrol on the migration and invasion of human osteosarcoma U-2OS cells in vitro. Cell migration and invasion were investigated using wound healing and Boyden chamber Transwell assays. We observed that Celastrol suppressed cell invasion and migration in human osteosarcoma U-2OS cells. Furthermore, protein expression levels of phosphorylated phosphatidylinositol 3-kinase (PI3K), Akt, inhibitor of $\kappa \mathrm{B}$ kinase $\alpha / \beta$, inhibitor of $\kappa \mathrm{B} \alpha$, nuclear factor- $\kappa \mathrm{B}(\mathrm{NF}-\kappa \mathrm{B}$ subunit p65) and matrix metalloproteinase (MMP)-2 and -9 were measured by western blot analysis. We observed that the PI3K/Akt/NF- $\mathrm{B}$ signaling pathway was inhibited following Celastrol treatment. In addition, the expression levels of MMP-2 and -9 proteins were also
\end{abstract}

Correspondence to: Dr Bin Zhang or Professor Min Dai, Department of Orthopedics, The First Affiliated Hospital of Nanchang University, Artificial Joints Engineering and Technology Research Center of Jiangxi Province, 17 Yong Wai Zheng Street, Nanchang, Jiangxi 330006, P.R. China

E-mail: 1207672246@qq.com

E-mail: 1135547344@qq.com

*Contributed equally

Key words: Celastrol, osteosarcoma, migration, invasion, matrix metalloproteinases, phosphatidylinositol 3-kinase/Akt reduced significantly following Celastrol treatment. Therefore, we confirmed that Celastrol suppressed osteosarcoma U-2OS cell metastasis via downregulation of the PI3K/Akt/NF- $\kappa \mathrm{B}$ signaling pathway in vitro.

\section{Introduction}

Osteosarcoma is the most common primary malignant bone neoplasm in adolescents and young adults, and usually occurs in growing long bones such as the humerus, femur and tibia $(1,2)$. It is a highly aggressive tumor that metastasizes primarily to the lung $(3,4)$. The main cause of mortality in osteosarcoma is lung metastasis. In general, lung metastasis is a sign of deterioration (5). The prognosis is extremely poor owing to the lack of effective treatment methods. Therefore, innovative approaches that target invasion and metastasis, particularly to the lung, from the primary osteosarcoma site are urgently required. Until now, the molecular mechanisms of invasion and metastasis in osteosarcoma have remained unclear. Therefore, clarification of the molecular mechanisms of the pathogenesis and biology of metastatic osteosarcoma is a critical factor for improving the curative effect and identifying potential therapeutic targets.

Tumor invasion and metastasis are complicated processes, involving the activities of tumor cells and host cells, which are regulated by multiple tumor-related genes $(6,7)$. One of the most significant steps in the invasion and metastasis cascade involves the destruction of the extracellular matrix (ECM) and basement membranes, allowing tumor cells to invade into and grow at sites distant from the original tumor site (8-10). The interaction between ECM proteins (including collagen and fibronectin) and tumor cell surface receptors is a critical initial step in the invasion and metastasis process $(11,12)$. Tumor cells are able to express ECM-degrading enzymes, including matrix metalloproteinases (MMPs). MMPs have been demonstrated to play a key role in permitting cancer cells to invade through the ECM and form metastatic lesions. The protein expression levels of MMPs in certain tumors are considered as an index of tumor invasion and metastatic potential (13-16). Therefore, the control of MMP activity and adhesion to ECM components may prevent invasion and metastasis development. 
MMPs are a family of highly homologous protein-degrading zinc-dependent enzymes endopeptidases, among which MMP-2 and -9 are notably correlated with tumor invasion and metastasis $(17,18)$. A number of studies have demonstrated that MMP-2 and -9 are overexpressed in osteosarcoma, and promote osteosarcoma cell migration and invasion by degrading components of the ECM and basement membranes (19-21). A large number of studies reveal that the nuclear factor- $\kappa \mathrm{B}$ $(\mathrm{NF}-\kappa \mathrm{B})$ gene is an upstream regulator of MMPs, and is closely associated with tumor invasion and migration $(22,23)$. In addition, the phosphatidylinositol 3-kinase (PI3K)/Akt pathway is considered to be a significant regulatory factor in $\mathrm{NF}-\kappa \mathrm{B}$ activation. Notably, activation of Akt has been revealed to be critical for degradation of the inhibitor of $N F-\kappa B$ and $\kappa \mathrm{B}(\mathrm{I} \kappa \mathrm{B})(24,25)$. Therefore, the PI3K/Akt/NF- $\kappa \mathrm{B}$ signaling pathway may be a treatment target to suppress osteosarcoma cell invasion and migration.

Traditional Chinese medicine, a significant component of complementary and alternative medicine, may serve as a useful model for scientific inquiry since it has a standardized system of diagnostics and therapies, and is used worldwide. Celastrol is a triterpene extracted from the Chinese 'Thunder God Vine', which inhibits cancer cell growth and induces apoptosis in a number of cancer cell lines (26-29). In our previous studies, we demonstrated that Celastrol could induce apoptosis of human osteosarcoma cells via the mitochondrial-dependent pathway. In the present study, we identified that Celastrol could suppress osteosarcoma U-2OS cell metastasis via downregulation of the $\mathrm{PI} 3 \mathrm{~K} / \mathrm{Akt} / \mathrm{NF}-\kappa \mathrm{B}$ signaling pathway in vitro.

\section{Materials and methods}

Materials and reagents. Dulbecco's modified Eagle's medium (DMEM), fetal bovine serum (FBS), dimethyl sulphoxide (DMSO) and trypsin were purchased from Transgen (Beijing, China). Phosphate-buffered saline (PBS) was obtained from Solarbio (Beijing, China). Phosphatase inhibitor cocktail was purchased from Roche (Penzberg, Germany). Antibodies against phosphorylated PI3K, Akt, inhibitor of $\kappa \mathrm{B}$ kinase (IKK) $\alpha / \beta$, inhibitor of $\kappa \mathrm{B} \alpha(\mathrm{I} \kappa \mathrm{B} \alpha)$, nuclear factor- $\kappa \mathrm{B}(\mathrm{NF}-\kappa \mathrm{B}$ subunit $\mathrm{p} 65)$ and $\beta$-actin were purchased from Cell Signaling Technology, Inc. (Beverly, MA, USA), and antibodies against MMP-2 and -9 were purchased from Abcam (Cambridge, UK). Horseradish peroxidase (HRP)-conjugated secondary antibodies were purchased from Cell Signaling Technology, Inc. and ZSGB-BIO (Beijing, China). Matrigel was purchased from Becton-Dickinson (San Jose, CA, USA). The Transwell invasion chamber was purchased from Costar (Cambridge, MA, USA). Celastrol was obtained from Nanjing ZeLang Medical Technology Co., Ltd. (Nanjing, China). Stock solutions of Celastrol were prepared by dissolving the Celastrol powder in DMSO to a concentration of $1 \mathrm{M}$, and stored at $-20^{\circ} \mathrm{C}$. The working concentrations of Celastrol were made by diluting the stock solution with the culture medium. The final concentration of DMSO in the medium was $<0.5 \%$.

Cell culture. Human osteosarcoma U-2OS cell lines were obtained from the American Type Culture Collection (Manassas, VA, USA). Cells were grown in culture medium consisting of DMEM supplemented with $10 \% \mathrm{FBS}, 100 \mathrm{U} / \mathrm{ml}$ penicillin and $100 \mu \mathrm{g} / \mathrm{ml}$ streptomycin. They were all placed in a humidified atmosphere containing $5 \% \mathrm{CO}_{2}$ at $37^{\circ} \mathrm{C}$. The cells used in this study were subjected to less than 20 cell passages, and all cells used in this study were in the logarithmic phase. The present study was approved by the Ethical Review Committee of The First Affiliated Hospital of Nanchang University Medical School (Nanchang, China).

Boyden chamber Transwell assays. Invasion of U-2OS cells was determined using Matrigel-coated Transwell cell culture chambers $(8 \mu \mathrm{m}$ pore size). Briefly, cells were cultured for $24 \mathrm{~h}$ in DMEM, then collected and resuspended in serum-free medium. Isolated cells $\left(1 \times 10^{4}\right.$ cells/well) were then added to the upper chamber of the Transwell insert and treated with Celastrol $(0,2.5$ and $4 \mu \mathrm{M})$, and the lower wells were filled with complete growth medium. All samples were incubated for $48 \mathrm{~h}$ at $37^{\circ} \mathrm{C}$ in a humidified atmosphere with $95 \%$ air and $5 \% \mathrm{CO}_{2}$. Non-invading cells on the upper surface of the membranes were removed using a cotton swab, and invading cells on the lower surface of the membranes were fixed and counted under a phase-contrast microscope in three random fields (magnification, x200).

Wound healing assays. Migration of U-2OS cells was measured using wound healing assays. U-2OS cells ( $1 \times 10^{5}$ cells/well) were seeded in a six-well culture plate to form a confluent monolayer, and then cells were wounded with a sterile $200-\mu 1$ pipette tip. All cells in the plates were treated with Celastrol at final concentrations of $0,2.5$ and $4 \mu \mathrm{M}$, and then incubated in fresh DMEM with $1 \%$ FBS for $48 \mathrm{~h}$. Scratch wounds were then inspected using a phase-contrast microscope and images of each wound were captured.

Western blot analysis. U-2OS cells were seeded in six-well plates at a concentration of $2 \times 10^{5}$ cells/well. Following treatment with $0,2.5$ and $4 \mu \mathrm{M}$ Celastrol for $48 \mathrm{~h}$, cells were collected and lysed in RIPA buffer containing phenylmethane sulfonyl fluoride and phosphatase inhibitor cocktail. Each sample was centrifuged at $12,000 \mathrm{rpm}$ for $10 \mathrm{~min}$ at $4^{\circ} \mathrm{C}$ to remove cell debris and to collect the supernatant for immunoblotting. Protein concentrations were calculated using bovine serum albumin as the standard. The same amounts of proteins were loaded and separated by electrophoresis on $12 \%$ sodium dodecyl sulphate-polyacrylamide gels under a reducing condition using $100 \mathrm{~V}$ for $2 \mathrm{~h}$. Following electrophoresis, the proteins were transferred to polyvinylidene fluoride (PVDF) membranes in a tris-glycine transfer buffer using a semi-dry blotting system, and incubated with antibodies against phosphorylated PI3K, Akt, IKK $\alpha / \beta, \mathrm{I} \kappa \mathrm{B} \alpha, \mathrm{NF}-\kappa \mathrm{B}$ subunit p65, MMP-2, MMP-9 and $\beta$-actin $(1: 1,000)$ overnight at $4^{\circ} \mathrm{C}$. After washing the membranes in TBST three times, secondary HRP-conjugated antibodies were added at a 1:2000 dilution for $1 \mathrm{~h}$ at room temperature and the membranes were washed again in Tris-buffered saline and Tween-20 three times. Immunoreactive proteins were detected by enhanced chemiluminescence (ECL kit, Transgen, China) and exposed to X-ray film.

Statistical analysis. Each experiment was performed at least three times independently, and the quantitative data were 
A
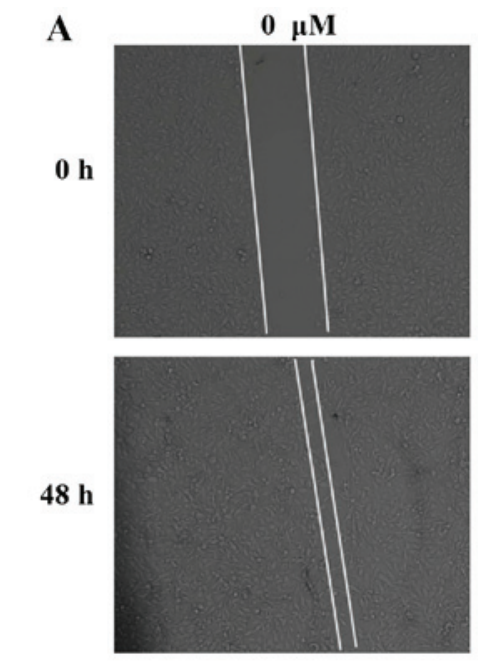

B
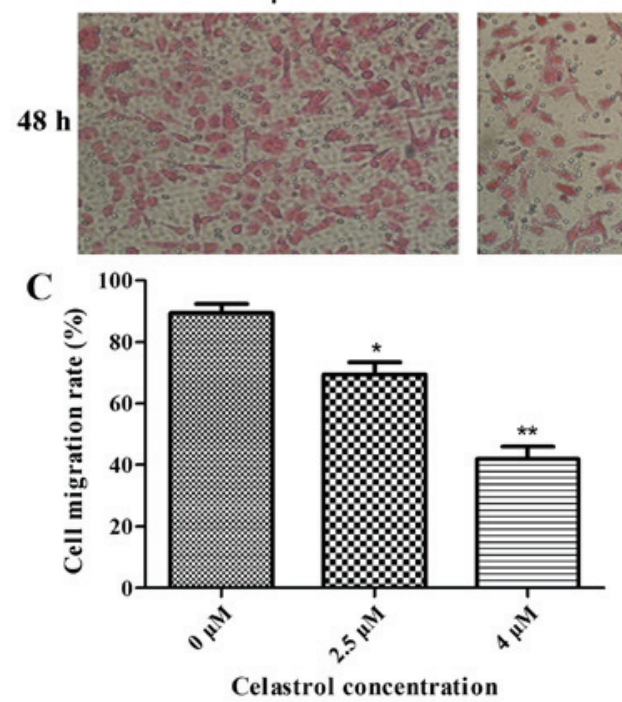

$2.5 \mu \mathrm{M}$
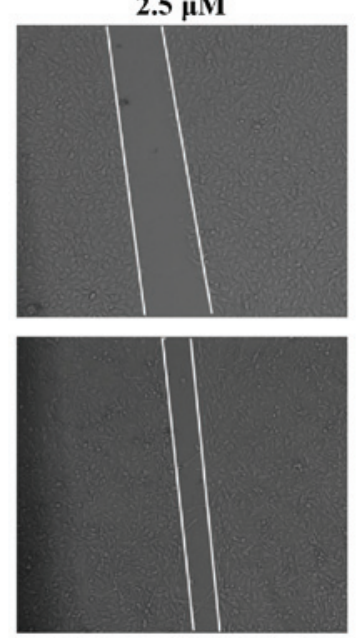

$2.5 \mu \mathrm{M}$

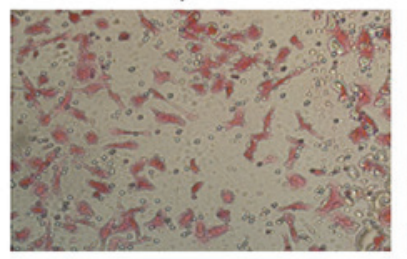

D

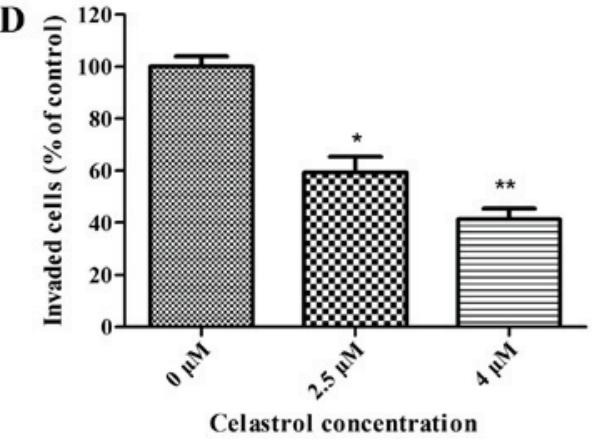

Figure 1. Celastrol inhibited cell migration and invasion in U-2OS cells. Cells were treated with $0,2.5$ and $4 \mu \mathrm{M}$ Celastrol for $48 \mathrm{~h}$. (A) Cell migration was examined by wound healing assays. (B) Cell invasion was examined using Matrigel-coated Transwell cell culture chambers. (C) Migration ability in U-2OS cells was quantified by counting the migrated cells in five random fields, and data are expressed as the means \pm standard deviation. (D) Invasion ability in $\mathrm{U}-2 \mathrm{OS}$ cells was quantified by counting the number of cells that migrated to or invaded the lower surface of the membranes under a phase-contrast microscope and represented the average of three experiments. Significant differences from the control $(0 \mu \mathrm{M})$ are indicated by ${ }^{*} \mathrm{P}<0.05$ and ${ }^{* * *} \mathrm{P}<0.01$.

expressed as the means \pm standard deviation. Data were analyzed using the SPSS package for Windows (version 17.0; SPSS, Inc., Chicago, IL, USA). Statistical analysis of the data was performed using Student's t-test and analysis of variance. $\mathrm{P}<0.05$ was considered to indicate a statistically significant difference.

\section{Results}

Celastrol inhibits cell migration and invasion in U-2OS cells. The effect of Celastrol on the migration and invasion of osteosarcoma U-2OS cells was measured by wound healing assays and Boyden chamber Transwell assays, respectively. U-2OS osteosarcoma cell lines were treated with Celastrol $(0$, 2.5 and $4 \mu \mathrm{M}$ ) for $48 \mathrm{~h}$. As shown in Fig. 1A and C, Celastrol inhibited the migration of U-2OS cells in a dose-dependent manner. In the Boyden chamber Transwell assays, Celastrol significantly reduced the invasion ability of U-2OS cells in a dose-dependent manner (Fig. 1B and D).
Celastrol decreases the expression of MMP-2 and MMP-9. It is well known that osteosarcoma cells produce MMPs to facilitate cell invasion and migration, among which MMP-2 and -9 play the most significant roles. We determined whether Celastrol could inhibit the expression of MMP-2 and -9 in U-2OS cells. As shown in Fig. 2, the results of western blot analysis revealed that Celastrol treatment caused a marked increase in MMP-2 and MMP-9 when compared with these levels in the control. This indicates that Celastrol inhibited cell migration and invasion in U-2OS cells by downregulating the expression of MMP-2 and -9 .

Effect of celastrol inhibition on PI3K/Akt/NF- $\kappa B$ signaling pathway. The effects of Celastrol on the levels of proteins associated with migration and invasion in U-2OS cells were examined using western blot analysis. The expression of phosphorylated PI3K, Akt, IKK $\alpha / \beta, \mathrm{I} \kappa \mathrm{B} \alpha$ and NF- $\kappa \mathrm{B}$ subunit $\mathrm{p} 65$ was significantly decreased following Celastrol treatment when compared with these levels in the control (Figs. 3 and 4). This indicates that Celastrol downregulates the expression of MMP-2 

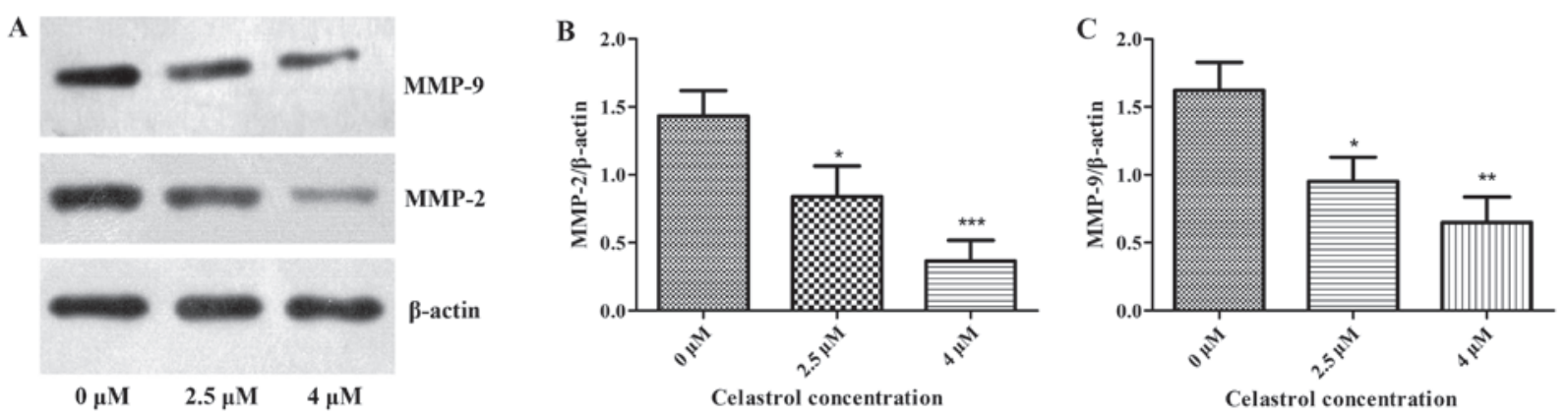

Figure 2. Effect of Celastrol on the protein expression levels of matrix metalloproteinase (MMP)-2 and MMP-9 in U-2OS cells, analyzed by western blot analysis. (A) The expression levels of MMP-2 and MMP-9 were significantly downregulated. $\beta$-actin was used as the internal control for western blot analysis. Protein expression levels of (B) MMP-2 and (C) MMP-9 in Celastrol-treated and control cells. The data shown are the averages \pm standard deviation (error bars), and significant differences from control cells are indicated by ${ }^{*} \mathrm{P}<0.05,{ }^{* * *} \mathrm{P}<0.01$ and ${ }^{* * * *} \mathrm{P}<0.001$
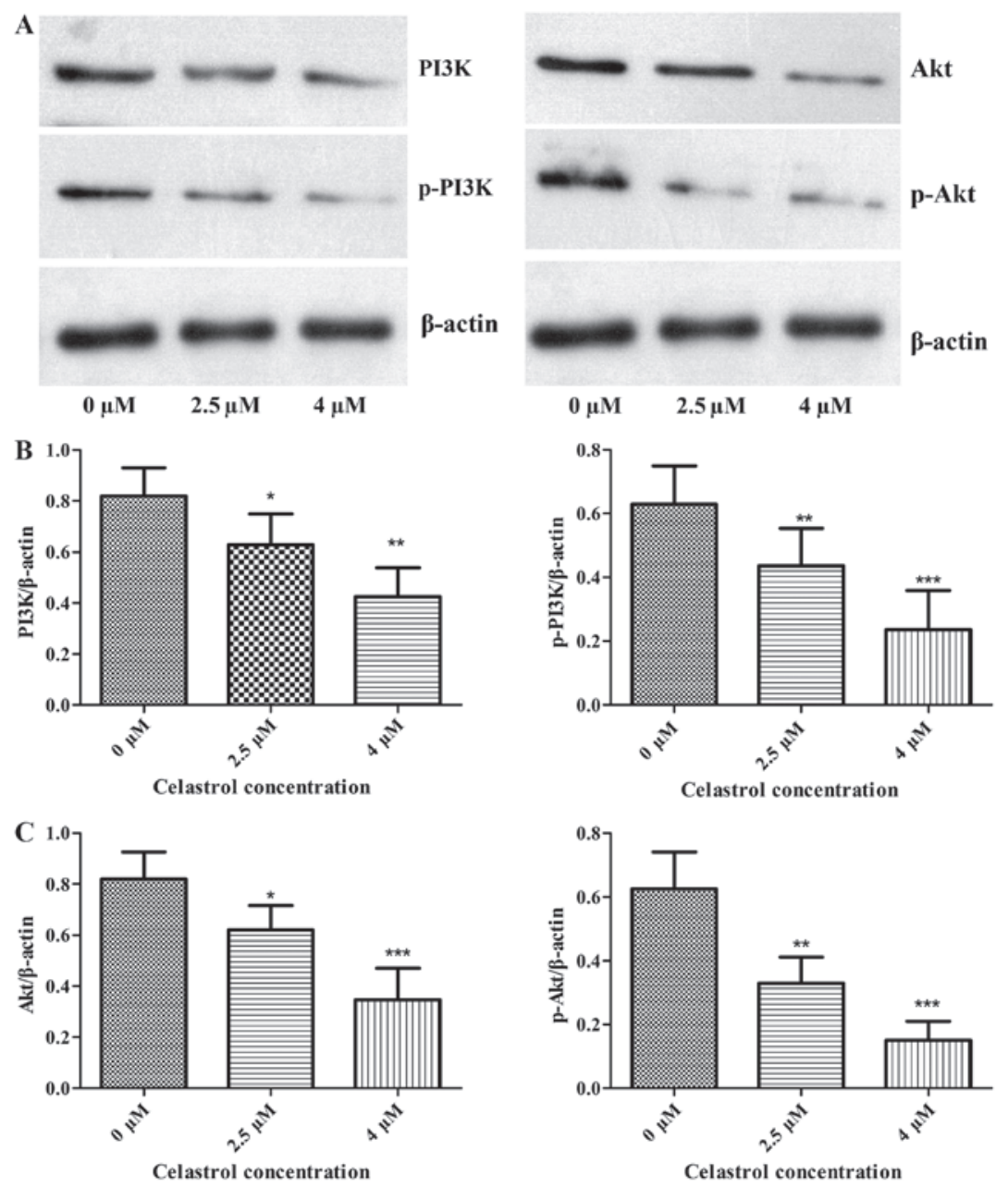

Figure 3. Effect of Celastrol inhibition on the phosphoinositide 3-kinase (PI3K)/Akt/nuclear factor (NF)- $\mathrm{kB}$ signaling pathway. (A) Protein expression levels of $\mathrm{PI} 3 \mathrm{~K}$, Akt and phosphorylated PI3K (p-PI3K) and Akt (p-Akt) were analyzed by western blot analysis. $\beta$-actin was used as the internal control. Quantification of protein expression levels of (B) PI3K and p-PI3K and (C) Akt and p-Akt in Celastrol-treated and control cells by western blot analysis. The data shown are the averages \pm standard deviation (error bars), and significant differences from control cells are indicated by ${ }^{*} \mathrm{P}<0.05,{ }^{* *} \mathrm{P}<0.01$ and ${ }^{* * * *} \mathrm{P}<0.001$

and -9 and inhibits cell migration and invasion by inhibiting the $\mathrm{PI} 3 \mathrm{~K} / \mathrm{Akt} / \mathrm{NF}-\mathrm{kB}$ signaling pathway in U-2OS cells.

\section{Discussion}

Osteosarcoma is the most common primary bone malignancy, particularly among children and adolescents, with an incidence of four to five cases per million (30,31). The symptoms of osteosarcoma are chronic bone pain and swelling in the leg or arm. The current therapeutic strategies for osteosarcoma include wide tumor excision, radiotherapy and neoadjuvant chemotherapy, all of which have notably improved the prognosis of patients with osteosarcoma (32-34). However, osteosarcoma has a high tendency for local aggression and to metastasize 

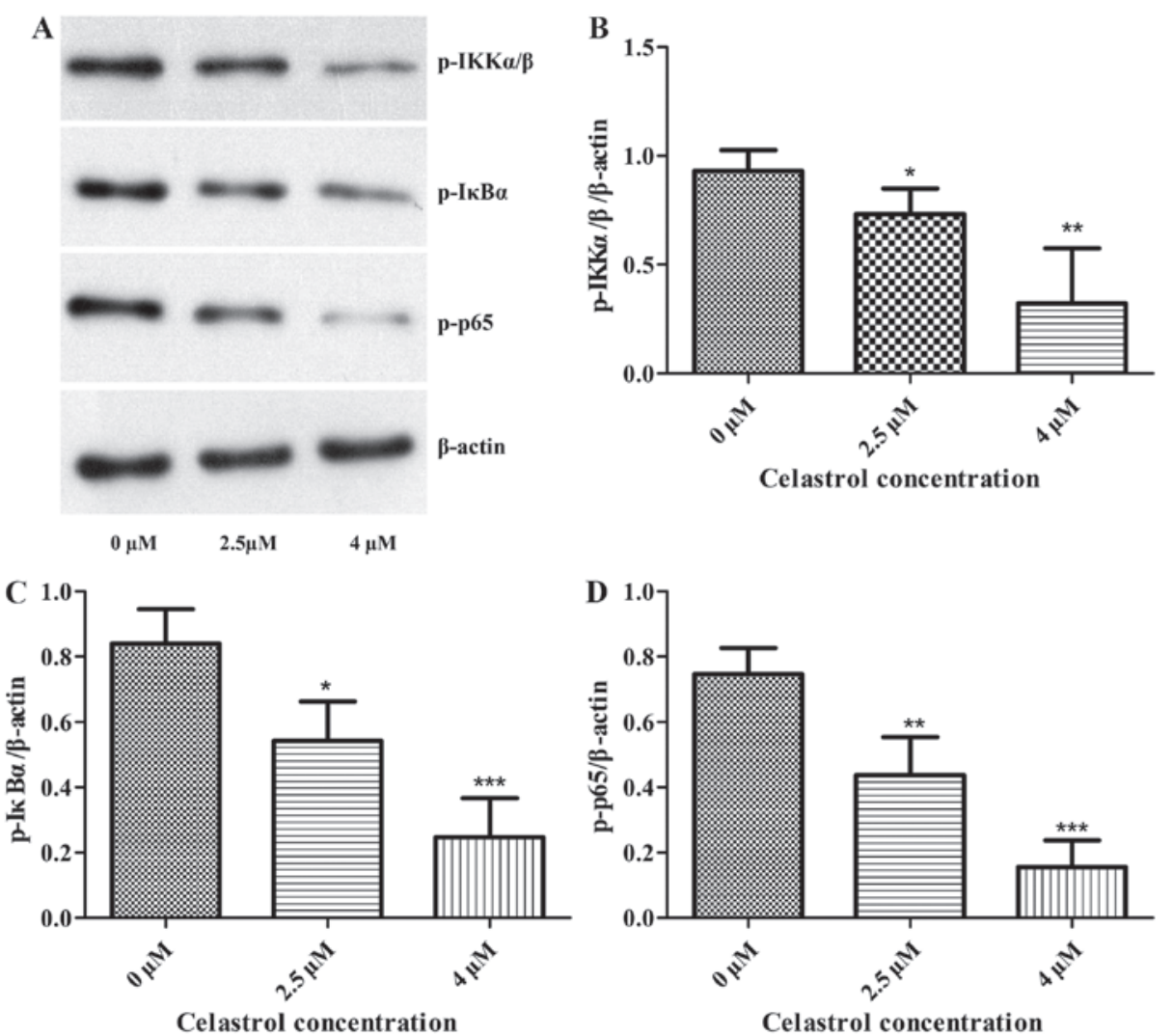

Figure 4. Effect of Celastrol inhibition on the phosphoinositide 3-kinase (PI3K)/Akt/nuclear factor (NF)-kB signaling pathway. (A) Protein expression levels of phosphorylated inhibitor of $\kappa \mathrm{B}$ kinase (IKK $\alpha / \beta)$, inhibitor of $\kappa \mathrm{B} \alpha(\mathrm{I} \kappa \mathrm{B} \alpha)$ and NF- $\kappa \mathrm{B}$ subunit $\mathrm{p} 65$ were analyzed by western blot analysis. $\beta$-actin was used as the internal control. (B) Protein expression levels of (B) phosphorylated (p-)IKK $\alpha / \beta$, (C) p-I $\mathrm{\kappa B} \alpha$ and (D) p-p65 in Celastrol-treated and control cells. The data shown are the averages \pm standard deviation (error bars), and significant differences from control cells are indicated by ${ }^{*} \mathrm{P}<0.05,{ }^{* * *} \mathrm{P}<0.01$ and ${ }^{* * * *} \mathrm{P}<0.001$.

to the lung and distant bones, which is a common cause of mortality $(35,36)$. Therefore, it is an urgent requirement to identify molecular mechanisms of invasion and metastasis in osteosarcoma, and to develop an effective adjuvant therapy to prevent osteosarcoma metastasis.

The interaction of cancer cells with the ECM is essential for metastasis, and this is performed through a series of steps including cell attachment, invasion and migration. These steps are regulated by an extremely complex molecular mechanism (37). The PI3K/Akt pathway is considered to be one of the most significant oncogenic pathways in human cancer. An increasing body of evidence has suggested that this pathway is frequently activated in osteosarcoma and contributes to disease development, including proliferation, invasion and migration $(38,39)$. A number of studies indicate that the inhibition of this pathway could downregulate the expression of $\mathrm{NF}-\kappa \mathrm{B}$, which is an upstream regulator of MMPs. Therefore, inhibition of this pathway could decrease the expressions of MMPs (22-25). It is well known that MMPs, which destroy the ECM and basement membranes, play a vital role in osteosarcoma invasion and metastasis. Therefore, we may infer that the PI3K/Akt/NF- $\mathrm{B}$ signaling pathway may be a treatment target to suppress osteosarcoma cell invasion and migration.

Celastrol, a triterpene, is an active component extracted from the traditional Chinese medicine 'Thunder God Vine', and has been used in the treatment of autoimmune and neurodegenerative diseases (40-42). Celastrol has previously attracted great attention due to its significant anticancer activity in vitro and in vivo, including the induction of apoptosis in a number of cancer cell lines (26-29). In our previous studies, we demonstrated that Celastrol could induce apoptosis of human osteosarcoma cells via the mitochondrial-dependent pathway (43). However, the effects of Celastrol on the migration and invasion of human osteosarcoma are still to be elucidated. In previous studies, the IC50 value for $\mathrm{U}-2 \mathrm{OS}$ cells treated with Celastrol was $2.5 \mu \mathrm{M}$ at $48 \mathrm{~h}$ in the MTT assay (43). Therefore, U-2OS cells were treated with Celastrol at concentrations of $0,2.5$ and $4 \mu \mathrm{M}$ for $48 \mathrm{~h}$ in the present study.

In the present study, cell migration and invasion were assessed by wound healing and Boyden chamber Transwell assays. The results revealed that the migratory and invasive capabilities were inhibited by Celastrol. These results indicate that Celastrol may be an effective agent for chemotherapy in the treatment of osteosarcoma. Furthermore, protein expression levels of phosphorylated PI3K, Akt, IKK $\alpha / \beta, \mathrm{I} \kappa \mathrm{B} \alpha, \mathrm{NF}-\kappa \mathrm{B}$ subunit p65 and MMP-2 and -9 were assessed by western blot analysis. The results revealed that the PI3K/Akt/NF- $\kappa \mathrm{B}$ signaling pathway was inhibited following Celastrol treatment. In addition, the expression levels of MMP-2 and -9 proteins were also markedly reduced following Celastrol treatment.

Taken together, our findings suggest that Celastrol could suppress osteosarcoma cell migration and invasion via downregulation of the $\mathrm{PI} 3 \mathrm{~K} / \mathrm{Akt} / \mathrm{NF}-\kappa \mathrm{B}$ signaling pathway in vitro, and that Celastrol may be an effective chemotherapeutic agent for osteosarcoma. In addition, further experiments on the in vivo effect of Celastrol on U-2OS xenograft tumors in nude mice are in progress. 


\section{Acknowledgements}

This project was supported by the Natural Science Foundation of Jiangxi Province (20132BAB205081), the Foundation of Health Department of Jiangxi Province on traditional Chinese medicine (2012A136) and the Engineering Technology Research Center Construction Project of Jiangxi Province (20132BCD40026).

\section{References}

1. Damron TA, Ward WG and Stewart A: Osteosarcoma, chondrosarcoma, and Ewing's sarcoma: National Cancer Data Base Report. Clin Orthop Relat Res 459: 40-47, 2007.

2. Poletajew S, Fus L and Wasiutyński A: Current concepts on pathogenesis and biology of metastatic osteosarcoma tumors. Ortop Traumatol Rehabil 13: 537-545, 2011 (In English and Polish).

3. Gill J, Ahluwalia MK, Geller D and Gorlick R: New targets and approaches in osteosarcoma. Pharmacol Ther 137: 89-99, 2013.

4. Guise TA, O'Keefe R, Randall RL and Terek RM: Molecular biology and therapeutics in musculoskeletal oncology. J Bone Joint Surg Am 91: 724-732, 2009.

5. Salah S and Toubasi S: Factors predicting survival following complete surgical remission of pulmonary metastasis in osteosarcoma. Mol Clin Oncol 3: 157-162, 2015.

6. Stefanatos RK and Vidal M: Tumor invasion and metastasis in Drosophila: a bold past, a bright future. J Genet Genomics 38: 431-438, 2011.

7. Mareel M, Oliveira MJ and Madani I: Cancer invasion and metastasis: interacting ecosystems. Virchows Arch 454: 599-622, 2009.

8. Shen A, Zhang Y, Yang H, Xu R and Huang G: Overexpression of ZEB1 relates to metastasis and invasion in osteosarcoma. J Surg Oncol 105: 830-834, 2012.

9. Watanabe H: Extracellular matrix-regulation of cancer invasion and metastasis. Gan To Kagaku Ryoho 37: 2058-2061, 2010 (In Japanese).

10. Lin YM, Chang ZL, Liao YY, Chou MC and Tang CH: IL-6 promotes ICAM-1 expression and cell motility in human osteosarcoma. Cancer Lett 328: 135-143, 2013.

11. van Zijl F, Krupitza G and Mikulits W: Initial steps of metastasis: cell invasion and endothelial transmigration. Mutat Res 728 23-34, 2011.

12. Willis AL, Sabeh F, Li XY and Weiss SJ: Extracellular matrix determinants and the regulation of cancer cell invasion stratagems. J Microsc 251: 250-260, 2013.

13. Polette M, Nawrocki-Raby B, Gilles C, Clavel C and Birembaut P: Tumour invasion and matrix metalloproteinases. Crit Rev Oncol Hematol 49: 179-186, 2004

14. Shuman Moss LA, Jensen-Taubman S and Stetler-Stevenson WG: Matrix metalloproteinases: changing roles in tumor progression and metastasis. Am J Pathol 181: 1895-1899, 2012.

15. Lynch CC: Matrix metalloproteinases as master regulators of the vicious cycle of bone metastasis. Bone 48: 44-53, 2011.

16. Halbersztadt A, Haloń A, Pajak J, Robaczyński J, Rabczynski J and St Gabryś M: The role of matrix metalloproteinases in tumor invasion and metastasis. Ginekol Pol 77: 63-71, 2006 (In Polish).

17. Khasigov PZ, Podobed OV, Gracheva TS, Salbiev KD, Grachev SV and Berezov TT: Role of matrix metalloproteinases and their inhibitors in tumor invasion and metastasis. Biochemistry (Mosc) 68: 711-717, 2003.

18. Deryugina EI and Quigley JP: Matrix metalloproteinases and tumor metastasis. Cancerr Metastasis Rev 25: 9-34, 2006.

19. Korpi JT, Hagström J, Lehtonen N, Parkkinen J, Sorsa T, Salo T and Laitinen M: Expression of matrix metalloproteinases-2, -8, $-13,-26$, and tissue inhibitors of metalloproteinase-1 in human osteosarcoma. Surg Oncol 20: e18-e22, 2011.

20. Bjørnland K, Flatmark K, Pettersen S, Aaasen AO, Fodstad O and Maelandsmo GM: Matrix metalloproteinases participate in osteosarcoma invasion. J Surg Res 127: 151-156, 2005.

21. Loukopoulos P, O'Brien T, Ghoddusi M, Mungall BA and Robinson WF: Characterisation of three novel canine osteosarcoma cell lines producing high levels of matrix metalloproteinases. Res Vet Sci 77: 131-141, 2004.

22. Felx M, Guyot MC, Isler M, Turcotte RE, Doyon J, Khatib AM, Leclerc S, Moreau A and Moldovan F: Endothelin-1 (ET-1) promotes MMP-2 and MMP-9 induction involving the transcription factor NF-kappaB in human osteosarcoma. Clin Sci (Lond) 110: 645-654, 2006.
23. Zhang XX, Fu Z, Zhang Z, Miao C, Xu P, Wang T, Yang L and Cheng S: Microcystin-LR promotes melanoma cell invasion and enhances matrix metalloproteinase-2/-9 expression mediated by NF- $\kappa B$ activation. Environ Sci Technol 46: 11319-11326, 2012.

24. Ahmad A, Biersack B,Li Y,Kong D, Bao B, SchobertR, Padhye SB and Sarkar FH: Targeted regulation of PI3K/Akt/mTOR/NF-kB signaling by indole compounds and their derivatives: mechanistic details and biological implications for cancer therapy. Anticancer Agents Med Chem 13: 1002-1013, 2013.

25. Kuan YH, Huang FM, Li YC and Chang YC: Proinflammatory activation of macrophages by bisphenol A-glycidyl-methacrylate involved NF- $\mathrm{BB}$ activation via PI3K/Akt pathway. Food Chem Toxicol 50: 4003-4009, 2012.

26. Shrivastava S, Jeengar MK, Reddy VS, Reddy GB and Naidu VG: Anticancer effect of celastrol on human triple negative breast cancer: possible involvement of oxidative stress, mitochondrial dysfunction, apoptosis and PI3K/Akt pathways. Exp Mol Pathol 98: 313-327, 2015.

27. Li PP, He W, Yuan PF, Song SS, Lu JT and Wei W: Celastrol induces mitochondria-mediated apoptosis in hepatocellular carcinoma Bel-7402 cells. Am J Chin Med 43: 137-148, 2015.

28. Mi C, Shi H, Ma J, Han LZ, Lee JJ and Jin X: Celastrol induces the apoptosis of breast cancer cells and inhibits their invasion via downregulation of MMP-9. Oncol Rep 32: 2527-2532, 2014.

29. Zhao X, Gao S, Ren H, Huang H, Ji W and Hao J: Inhibition of autophagy strengthens celastrol-induced apoptosis in human pancreatic cancer in vitro and in vivo models. Curr Mol Med 14: 555-563, 2014.

30. Sampo M, Koivikko M, Taskinen M, Kallio P, Kivioja A, Tarkkanen $\mathrm{M}$ and Böhling T: Incidence, epidemiology and treatment results of osteosarcoma in Finland - a nationwide population-based study. Acta Oncol 50: 1206-1214, 2011.

31. Mirabello L, Troisi RJ and Savage SA: International osteosarcoma incidence patterns in children and adolescents, middle ages and elderly persons. Int J Cancer 125: 229-234, 2009.

32. Dai X, Ma W, He X and Jha RK: Review of therapeutic strategies for osteosarcoma, chondrosarcoma, and Ewing's sarcoma. Med Sci Monit 17: RA177-RA190, 2011.

33. Ando K, Heymann MF, Stresing V, Mori K, Rédini F and Heymann D: Current therapeutic strategies and novel approaches in osteosarcoma. Cancers (Basel) 5: 591-616, 2013.

34. Lamoureux F, Trichet V, Chipoy C, Blanchard F, Gouin F and Redini F: Recent advances in the management of osteosarcoma and forthcoming therapeutic strategies. Expert Rev Anticancer Ther 7: 169-181, 2007.

35. Li Y, Liao Q, Li K, Zhong D, Weng X and Mi M: Knockdown of endothelin A receptor expression inhibits osteosarcoma pulmonary metastasis in an orthotopic xenograft mouse model. Mol Med Rep 5: 1391-1395, 2012.

36. Kato H, Wakabayashi H, Naito Y, Kato S, Nakagawa T, Matsumine A and Sudo A: Anti-tumor necrosis factor therapy inhibits lung metastasis in an osteosarcoma cell line. Oncology 88: 139-146, 2015.

37. Daw NC, Chou AJ, Jaffe N, Rao BN, Billups CA, Rodriguez-Galindo C, Meyers PA and Huh WW: Recurrent osteosarcoma with a single pulmonary metastasis: a multi-institutional review. Br J Cancer 112: 278-282, 2015.

38. Hou CH, Lin FL, Tong KB, Hou SM and Liu JF: Transforming growth factor alpha promotes osteosarcoma metastasis by ICAM-1 and PI3K/Akt signaling pathway. Biochem Pharmacol 89: 453-463, 2014.

39. Zhang J, Yu XH, Yan YG, Wang C and Wang WJ: PI3K/Akt signaling in osteosarcoma. Clin Chim Acta 444: 182-192, 2015.

40. Allison AC, Cacabelos R, Lombardi VR, Alvarez XA and Vigo C: Celastrol, a potent antioxidant and anti-inflammatory drug, as a possible treatment for Alzheimer's disease. Prog Neuropsychopharmacol Biol Psychiatry 25: 1341-1357, 2001.

41. Cleren C, Calingasan NY, Chen J and Beal MF: Celastrol protects against MPTP- and 3-nitropropionic acid induced neurotoxicity. J Neurochem 94: 995-1004, 2005.

42. Jung HW, Chung YS, Kim YS and Park YK: Celastrol inhibits production of nitric oxide and proinflammatory cytokines through MAPK signal transduction and NF-kappaB in LPS-stimulated BV-2 microglial cells. Exp Mol Med 39: 715-721, 2007.

43. Yu X, Zhou X, Fu C, Wang Q, Nie T, Zou F, Guo R, Liu H, Zhang B and Dai M: Celastrol induces apoptosis of human osteosarcoma cells via the mitochondrial apoptotic pathway. Oncol Rep 34: 1129-1136, 2015. 